Submitted to Science of the Total Environment

on September 29, 2015

Revision submitted on December 13, 2015

Second revision submitted on January 22, 2016

\title{
Radioactive Cs in the estuary sediments near Fukushima Daiichi Nuclear Power Plant
}

Shinya Yamasaki ${ }^{1, *}$, Junpei Imoto $^{2}$, Genki Furuki ${ }^{2}$, Asumi Ochiai ${ }^{2}$, Toshihiko Ohnuki ${ }^{3}$, Keisuke, Sueki $^{1}$, Kenji Nanba ${ }^{4}$, Rodney C. Ewing ${ }^{5}$, and Satoshi Utsunomiya ${ }^{2}$

${ }^{1}$ Faculty of Pure and Applied Sciences and Center for Research in Isotopes and Environmental Dynamics, University of Tsukuba, 1-1-1 Tennodai, Tsukuba, Ibaraki 305-8577 Japan

${ }^{2}$ Department of Chemistry, Kyushu University, 6-10-1 Hakozaki, Higashi-ku, Fukuoka 812-8581 Japan

${ }^{3}$ Advanced Science Research Center, Japan Atomic Energy Agency, Shirakata Shirane 2-4, Tokai, Ibaraki 319-1195, Japan

${ }^{4}$ Department of Environmental Management, Faculty of Symbiotic System Science, Fukushima University, Kanayagawa 1, Fukushima, 960-1296 Japan

${ }^{5}$ Department of Geological Sciences and Center for International Security and Cooperation, Stanford University, Stanford, CA 94305-2115 USA

*E-mail: s-yamasaki@ied.tsukuba.ac.jp (S. Y.) 


\begin{abstract}
The migration and dispersion of radioactive Cs (mainly ${ }^{134} \mathrm{Cs}$ and ${ }^{137} \mathrm{Cs}$ ) are of critical concern in the area surrounding the Fukushima Daiichi Nuclear Power Plant (FDNPP). Considerable uncertainty remains in understanding the properties and dynamics of radioactive Cs transport by surface water, particularly during rainfall-induced flood events to the ocean. Physical and chemical properties of unique estuary sediments, collected from the Kuma River, $4.0 \mathrm{~km}$ south of the FDNPP, were quantified in this study. These were deposited after storm events and now occur as dried platy sediments on beach sand. The platy sediments exhibit median particle sizes ranging from 28 to 32 $\mu \mathrm{m}$. There is increasing radioactivity towards the bottom of the layers deposited; approximately 28 and $38 \mathrm{~Bq} \mathrm{~g}^{-1}$ in the upper and lower layers, respectively. The difference in the radioactivity is attributed to a larger number of particles associated with radioactive $\mathrm{Cs}$ in the lower part of the section, suggesting that radioactive $\mathrm{Cs}$ in the suspended soils transported by surface water has decreased over time.
\end{abstract}

Sequential chemical extractions showed that $\sim 90 \%$ of ${ }^{137} \mathrm{Cs}$ was strongly bound to the residual fraction in the estuary samples, whereas $60 \sim 80 \%$ of ${ }^{137} \mathrm{Cs}$ was bound to clays in the six paddy soils. This high concentration in the residual fraction facilitates ease of transport of clay and silt size particles through the river system. Estuary sediments consist of particles $<100 \mu \mathrm{m}$. Radioactive Cs desorption experiments using the estuary samples in artificial seawater revealed that $3.4 \pm 0.6 \%$ of

${ }^{137} \mathrm{Cs}$ was desorbed within 8 hours. More than $96 \%$ of ${ }^{137} \mathrm{Cs}$ remained strongly bound to clays. Hence, particle size is a key factor that determines the travel time and distance during the dispersion of ${ }^{137} \mathrm{Cs}$ in the ocean.

\title{
Key Words
}

Sequential extraction; Gamma spectrometry; Autoradiography; Suspended soils; Desorption experiment 


\section{Introduction}

A wide variety of radionuclides, such as ${ }^{134} \mathrm{Cs},{ }^{137} \mathrm{Cs},{ }^{131} \mathrm{I}$, and ${ }^{133} \mathrm{Xe}$, were released from the Fukushima Daiichi Nuclear Power Plant (FNDPP) (Chino et al., 2011). However, ${ }^{137}$ Cs is the nuclide of the greatest concern, because it is a major contributor to radiation dose with its half-life of 30.1 years. Cesium-137 has a beta decay mode within a short period of time (approximately two minutes) followed by isomeric transition to stable ${ }^{137} \mathrm{Ba}$. Because of this it is easily detected by gamma ray emission during the isomeric transition. Many researchers have suggested that the occurrence and geochemical behavior of radioactive Cs (mainly ${ }^{134} \mathrm{Cs}$ and ${ }^{137} \mathrm{Cs}$ ) in the surface environment is critical to predicting its distribution and subsequent radiation exposures (Ueda et al., 2013; Kato et al., 2012; Aoyama et al., 2012; Tazoe et al., 2012; Kaneko et al., 2015).

Radioactive Cs supplied by the FDNPP in wet deposition was immediately adsorbed onto soil particles and fixed in the top $\sim 5 \mathrm{~cm}$ of surface soil where it remains (Fujiwara et al., 2012; Teramage et al., 2014; Mishra et al., 2015; Takahashi et al., 2015). Soluble Cs ion, regardless of the isotope, bonds strongly to the sheet-structure of alumino-silicates, such as weathered mica, illite, and vermiculite due to the presence of frayed-edge negatively charged sites (FES) (Sawhney, 1970; Cremers et al., 1988; Kogure et al., 2012); thus, it is difficult to desorb the strongly-bound Cs from the clays by chemical treatment. After sequential chemical extraction of ${ }^{137} \mathrm{Cs}$ sorbed to clays using ammonium acetate, hydrogen peroxide, and nitric acid, more than $60 \%$ of the ${ }^{137} \mathrm{Cs}$ was retained in the insoluble fraction (Hou et al., 2003; Kozai et al; 2012; Saito et al., 2014), which is mainly ${ }^{137} \mathrm{Cs}$ sorbed to clays.

Regular air-craft radiation monitoring over the area within $30 \mathrm{~km}$ from the FDNPP revealed that the measured radioactivity dramatically decreased during the period from 2011 to 2012 (NRA, Japan, 2015). The decrease in the level of radioactivity was much greater than expected based on the decay rates of ${ }^{134} \mathrm{Cs}$ and ${ }^{137} \mathrm{Cs}$, indicating that the radioactive Cs was physically mobile in the 
Fukushima surface environment (Yamaguchi et al., 2014). We hypothesized this was due to erosion of surface soil minerals with radioactive Cs by heavy rain events including typhoons in September 2011 and in the summer of 2013; and transport by flow into the ocean through the Natsui and Same Rivers (Nagao et al., 2013), as well as the Niida, Mano, Odaka, and Ohta Rivers (Evrard et al., 2014) (Fig. 1). In addition, Tanka et al. (2015) indicated radioactivity concentration of ${ }^{137} \mathrm{Cs}$ increased with decreasing particle size. A recent study proposed a transportation model in which radioactive Cs moves through rivers and ocean based on coagulation and precipitation due to the salinity of the offshore waters (Minoura et al., 2014). Although these conceptual model and bulk estimation of radioactive Cs flux have been established, the nature of radioactive Cs associated with transported soil particles remains unclear.

In the offshore region of the Kuma River, ${ }^{137} \mathrm{Cs}$ radioactivity associated with ocean floor sediments decreased with distance from the Kuma River estuary in the range of $1-5 \mathrm{~km}$, but increased with the distance in the range from 10 to $20 \mathrm{~km}$ (TEPCO report 2012). In order to elucidate the chemical state of radioactive Cs, especially ${ }^{137} \mathrm{Cs}$, on the transported particles by a river during high-flow events, the present study investigated unique sediments collected from an estuary $4.0 \mathrm{~km}$ south of the FDNPP by a variety of analytical techniques, including a sequential chemical extraction method, scanning electron microscopy, powder X-ray diffraction, and autoradiography. A radioactive Cs leaching experiment was also completed on the same samples using artificial seawater in order to qualitatively evaluate the occurrence and desorption process of radioactive Cs when the soil particles associated with radioactive Cs were transported to the ocean.

\section{Experimental}

\subsection{Samples}


Estuary sediments were collected from the Kuma River (1). For comparison, a riverbed sediment was collected from downstream in the Odaka River (2), and six paddy soils (3-8) were collected from the contaminated area (Fig. 1). Paddy soils were analyzed as example of the Cs associated with surface soils (Table Supplemental Information 1 (Table SI1)). Four estuary samples were collected from the Kuma River that is south of FDNPP on July 3, 2014. The total length of the Kuma River is $\sim 25 \mathrm{~km}$, and the river catchment area is about $70 \mathrm{~km}^{2}$ (Teranaka et al., 1990). The Kuma River Estuary is located $\sim 4.0 \mathrm{~km}$ south of FDNPP. Upstream of the Kuma River is the western part of Futaba County, which includes the highly contaminated area as far as $\sim 20 \mathrm{~km}$ from the FDNPP. The Kuma River bends at a right angle before flowing into the ocean. There, the beach sand is covered with dry, muddy sediments that form as layers with fractures (Figure Supplemental information 1 (Fig. SI1a). The thickness of the layers decreased from $\sim 2 \mathrm{~cm}$ with increasing distance from river (Fig. SI1b, Table SI2). Four samples were collected from the layered sequence in the Kuma River estuary, as well as a beach sand sample for reference (Fig. SI2). Twenty grams of samples were crushed and sieved with a $2 \mathrm{~mm}$ mesh filter for analysis after drying the samples in our laboratory. .

Six paddy soils and one riverbed sediment from the Odaka River were collected from the surface to as deep as $\sim 2 \mathrm{~cm}$. These samples were also sieved with $2 \mathrm{~mm}$ mesh filter. All analyses were performed after August 2014. Paddy soils and the Odaka River sediments were treated and kept as follows. Soil samples were completely air dried for more than one week at room temperature. After drying, samples were sieved with $2 \mathrm{~mm}$ mesh filter and kept in a dark room until used in the experiment.

\subsection{Sequential chemical extraction method and gamma spectrometry}

A sequential extraction method using chemical reagents was applied to the samples (Tessier et al., 1979; Hou et al., 2003) in order to isolate and quantify the radioactive Cs in each extracted 
fraction. All chemical reagents were analytical grade purchased from Wako Pure Chemical Industries Ltd., Japan. Radioactive Cs was separated into six chemical forms: water soluble (F1), ion exchangeable (F2), carbonate binding (F3), metal oxides binding (F4), organic matter binding (F5) and residue (F6). Each sample was analyzed with one replicate in this method. The extraction procedures were as follows:

\section{F1: Water soluble fraction}

Five grams of the sieved soil were immersed in $100 \mathrm{~cm}^{3}$ of ultra-pure water $(\mathrm{pH} 6.05$ at $20.0^{\circ} \mathrm{C}$ ); and the suspension was shaken for 2 hours using rotary shaker at the rate of $100 \mathrm{rpm}$ at room temperature $\left(25 \pm 1^{\circ} \mathrm{C}\right)$. The suspension was centrifuged at $3000 \mathrm{rpm}$ for $10 \mathrm{~min}$ (Hitachi himac CF7D2), and the supernatant was filtered through a $25 \mathrm{~nm}$ membrane filter. Sediment of the centrifugation was rinsed by $20 \mathrm{~cm}^{3}$ ultra-pure water to recover completely the radioactive Cs desorbed in this procedure, and then the rinsed solution was also filtered through the $25 \mathrm{~nm}$ membrane filter together with the first supernatant. After filtration, the filter was added to a bottle to with suspended particles and colloidal substances $(>25 \mathrm{~nm})$. The filtrate was put into a plastic container (U-8 screw type, AS ONE corp. JAPAN) and analyzed for ${ }^{137} \mathrm{Cs}$ radioactivity using a gamma-ray spectrometry. The residue and the filter were used in the next step.

\section{F2: Ion exchangeable fraction}

One hundred $\mathrm{cm}^{3}$ of $1.0 \mathrm{~mol} \mathrm{dm}^{-3} \mathrm{NH}_{4} \mathrm{OAc}$ adjusted to $\mathrm{pH} 8.0$ was added to the residue of $\mathrm{F} 1$. The following incubation, centrifugation, and first filtration processes were performed in the same manner as the F1 fraction described above. The first residue was rinsed by $20 \mathrm{~cm}^{3}$ of $1.0 \mathrm{~mol} \mathrm{dm}^{-3}$ ammonium acetate $(\mathrm{pH} 8.0)$ and then centrifuged at $3000 \mathrm{rpm}$ for 10 minutes. The supernatants were filtered using a $25 \mathrm{~nm}$ membrane filter, and filtrates were put into a U-8 container then analyzed by a gamma spectroscopy. The filter was added to the residue and the mixture was used in the third step.

\section{F3: Carbonate binding fraction}


One hundred $\mathrm{cm}^{3}$ of $1.0 \mathrm{~mol} \mathrm{dm}^{-3} \mathrm{NH}_{4} \mathrm{OAc}$ was adjusted to $\mathrm{pH} 5.0$ and added to the residue of F3. The suspension was shaken for 6 hours at room temperature. The reacted solution was centrifuged at $3000 \mathrm{rpm}$ for 10 minutes, and the supernatant was filtered using a $25 \mathrm{~nm}$ membrane filter. The residue was rinsed with $20 \mathrm{~cm}^{3}$ of $1.0 \mathrm{M} \mathrm{NH}_{4} \mathrm{OAc}(\mathrm{pH} 5.0)$ then centrifuged at $3000 \mathrm{rpm}$ for 10 minutes. The supernatants were filtered together, and mixed with the residue and used in the fourth step. The filtrates were analyzed using gamma spectroscopy.

\section{F4: Metal oxides binding fraction}

The residue was put into a $500 \mathrm{~cm}^{3}$ glass media bottle with $100 \mathrm{~cm}^{3}$ of ultrapure water. In this stage, all the filters were removed. Then, the $100 \mathrm{~cm}^{3}$ of $0.04 \mathrm{~mol} \mathrm{dm}^{-3}$ hydroxylamine hydrochloride in $25 \mathrm{v} / \mathrm{v} \%$ acetic acid was adjusted to $\mathrm{pH} 2.0$ and added to the residue. The mixture was stirred for 6 hours at $95 \pm 5^{\circ} \mathrm{C}$ using a magnetic stirrer. In this process, the screw cap of the glass bottle was slightly closed to avoid the loss of water through evaporation, but not to increase the bottle pressure. After cooling the bottle with running water, the suspension was put into a 250 $\mathrm{cm}^{3}$ plastic bottle followed by the centrifugation at $3000 \mathrm{rpm}$ for 10 minutes. The supernatant was filtered using a $25 \mathrm{~nm}$ membrane filter. The residue was rinsed with ultrapure water, and the suspension was centrifuged at $3000 \mathrm{rpm}$ for 10 minutes. The filtrates were put into a U-8 container and analyzed by a gamma spectrometry. The residue and membrane filter were put into the glass bottle again to be used for the next step.

\section{F5: Organic matter binding fraction}

Twenty $\mathrm{cm}^{3}$ of $30 \% \mathrm{H}_{2} \mathrm{O}_{2}$ solution adjusted to $\mathrm{pH} 2.0$ with nitric acid was added to the glass bottle containing the residue of F4. In this stage, all the filters were removed from the glass bottle. The suspension was stirred for 6 hours at $95 \pm 5{ }^{\circ} \mathrm{C}$ using hot stirrer. During the incubation, $100 \mathrm{~cm}^{3}$ of the hydrogen peroxide solution was gradually and carefully added so that the solution did not bubble over from the bottle. After cooling the bottle to room temperature by exposure to running 
water, the reacted solution was put into a plastic bottle followed by centrifugation at $3000 \mathrm{rpm}$ for 10 min. The supernatant was filtered using a $25 \mathrm{~nm}$ membrane filter. Then, the $100 \mathrm{~cm}^{3}$ of $3.2 \mathrm{~mol} \mathrm{dm}^{-3}$ ammonium acetate in $20 \mathrm{v} / \mathrm{v} \%$ nitric acid solution adjusted to $\mathrm{pH} 2.0$ was added to the centrifugation residue. This suspension was incubated for one hour at room temperature at the rate of $100 \mathrm{rpm}$ using a rotary shaker. The incubated solution was centrifuged at $3000 \mathrm{rpm}$ for 10 minutes, and the supernatant filtered using a $25 \mathrm{~nm}$ membrane filter. The residue was rinsed with $20 \mathrm{~cm}^{3}$ of ultra-pure water and then centrifuged at $3000 \mathrm{rpm}$ for 10 minutes. The supernatant was also filtered with the membrane filter. The filtrate was put into a U-8 container and then analyzed by a gamma spectrometry, while the residue was further treated in the next step.

\section{F6- Residue}

All of the F5 residue was rinsed with ultra-pure water on the $25 \mathrm{~nm}$ membrane filter to desalinate the extractants. Then, the residue was put into a U-8 container and then completely dried at $60{ }^{\circ} \mathrm{C}$ in a thermostatic oven for 48 hours to obtain the dry mass of the residue. After drying, the radioactivity was measured by a gamma spectrometry.

\section{Gamma spectrometry}

The radioactivity of ${ }^{134} \mathrm{Cs}$ and ${ }^{137} \mathrm{Cs}$ in the six fractions obtained from the sequential extraction were analyzed using a gamma spectrometer equipped with a low background type germanium detector (EG\&G ORTEC Ltd., GMX30200, JAPAN). Radioactivity of ${ }^{134} \mathrm{Cs}$ and ${ }^{137} \mathrm{Cs}$ was deduced using a spectrum analyzing software (SEIKO EG\&G Ltd., Gamma Studio, JAPAN). The geometric efficiency and energy calibration of the gamma spectrometer were completed using the mixed standard isotope solutions (MX033MR) purchased from Japan Radioisotope Association (JRIA).

The radioactivity concentration of each fraction was calculated as follows;

${ }^{137} \mathrm{Cs}$ radioactivity concentration / $\mathrm{Bq} \mathrm{g}^{-1}$ 
$=$ radioactivity of each fraction $(\mathrm{Bq}) /$ dry weight of initial soil sample used in the experiment $(\mathrm{g})$ (Equation 1).

\subsection{Powder X-ray diffraction}

Samples for the powder X-ray diffraction were ground with an agate mortar for 20 minutes. The major mineral assemblage of the soils were identified by using a powder X-ray diffraction equipped with a $\mathrm{Cu}$ target $(\mathrm{Cu}-\mathrm{K} \alpha)$ and a reflected beam monochromator (RIGAKU corp., MultiFlex, JAPAN). The voltage and current were $40 \mathrm{kV}$ and $40 \mathrm{~mA}$. The scan range was from $3^{\circ}$ to $63^{\circ}$ with the scanning speed of $1^{\circ} \mathrm{min}^{-1}$ of $2 \theta$ and with the step interval of $0.02^{\circ}$.

\subsection{Microscopic analysis}

A piece of the platy sediment was mounted in the liquid polymer resin, and the mixture was solidified under reduced pressure using a vacuum pump overnight. The sample-mounted resin was cut in a vertical direction by using a microcutter (Maruto). The cross section was polished using a polishing sheet with decreasing roughness steps down to $1 \mu \mathrm{m}$ of diamond sheet. The polished specimen was analyzed using a scanning electron microscopy (SEM, SHIMADZU SS-550) equipped with energy dispersive X-ray spectroscopy (EDX). The SEM specimen was coated with carbon using a carbon coater (SANYU SC-701C) to ensure conductivity prior to observation. The EDX analysis was completed using a $15 \mathrm{kV}$ acceleration voltage.

\subsection{Size analysis}

Soil samples were roughly loosened by hand and then used for the size analysis by using a laser diffraction particle size analyzer (SHIMADZU corp., SALD-3100, Japan); $0.30 \mathrm{~g}$ of sample was dispersed into $100 \mathrm{~cm}^{3}$ tap water and stirred thoroughly for ten minutes using a magnetic stirrer. The 
suspension was added to the analyzer to reach optical diffraction intensity. After sonicating the solution for five minutes, the measurement was repeated three times for each sample. A dispersant was not used.

\subsection{X-ray fluorescence spectroscopy}

Elemental composition of bulk soil samples was determined using an energy dispersive X-ray spectrometer (Shimadzu corp., EDX-720, Japan) based on a fundamental parameter method (Afonin et al., 1992; Borkhodoev, 2002). The collimator diameter was set to $5 \mathrm{~mm}$. The accelerating voltage was set to $50 \mathrm{kV}$ for the determination of all the elements measured in this study. The measurement was performed for the 100 seconds of detection time under atmospheric conditions without spinning the sample. The elemental compositions were calculated to be oxides and normalized to $100 \%$ in total. It was difficult to detect $\mathrm{Na}$ and $\mathrm{Mg}$ due to the low sensitivity of the detector. Instead, $\mathrm{Na}$ and $\mathrm{Mg}$ contents were semi-quantitatively determined to be a few $\mathrm{wt} \%$ as oxides.. The samples were analyzed with 3 replicates for each sampling point.

\subsection{Autoradiography}

The platy sediments were mounted in resin and analyzed by autoradiography in order to visualize the distribution of radioactive Cs. The cross-section described above was covered with plastic wrap, faced on the imaging plate (GE healthcare, BAS IP series $20 \times 25 \mathrm{~cm}$ ), and exposed for 24 hours in a lead-shielded block. The imaging plate was scanned using an imaging plate reader (GE healthcare, FLA 9500) with the resolution of $50 \mu \mathrm{m}$. Autoradiography was also performed for the F6 fraction residue of estuary sample $\mathrm{C}$ after the sequential chemical extraction.

2.8. Desorption experiment of ${ }^{137} \mathrm{Cs}$ in a simulated seawater 
A desorption experiment of radioactive Cs was performed using artificial seawater in order to examine the process of ${ }^{137} \mathrm{Cs}$ release to the ocean. The artificial seawater was purchased from Wako Pure Chemical Industries (JAPAN, Daigo's Artificial Seawater SP for Marine Microalgae Medium), and the chemical composition is given in Table SI3. The $\mathrm{pH}$ of the artificial seawater was 6.8 . The $0.80 \mathrm{~g}$ of the powdered estuary sample was mixed with $40 \mathrm{~cm}^{3}$ of artificial seawater and incubated for 2 hours at room temperature on a rotary shaker at $100 \mathrm{rpm}$. Then, the suspension was centrifuged at $3000 \mathrm{rpm}$ for 10 minutes, and the supernatant was filtered by a $25 \mathrm{~nm}$ membrane filter. The filtrate was put into a U-8 container and analyzed by gamma spectrometry. The residual soil was used for the next leaching treatment. The treatment was repeated ten times, and total desorbed ${ }^{137} \mathrm{Cs}$ was calculated based on the measured ${ }^{137} \mathrm{Cs}$ radioactivity.

\section{Results}

\subsection{Characterization of the estuary samples}

The particle size distribution of estuary sample A is shown in Fig. SI3. The median value of particle size was determined to be $\sim 32 \mu \mathrm{m}$. Since the other samples B, C, and D revealed similar size distribution to that of the sample A, their median values are presented in Table SI2 (28 to $32 \mu \mathrm{m}$ ).

X-Ray diffraction patterns of estuary sediments A-D and beach sand are shown in Fig. 2a. The major components are quartz, feldspars and clays. Pattern focusing on the low angle from $3^{\circ}$ to $16^{\circ}$ (Fig. 2b) revealed the presence of clays with d-spacings of 7.1, 10.1 and $14.3 \AA$ in the estuary samples, but little of these phases were detected in the beach sand (Fig. 2b). The proportion of the major mineral compositions showed no variation from the river to the beach.

Chemical composition of the estuary sediment obtained by XRF measurements is summarized in Table 1. As inferred from XRD results, all estuary sediments were mainly composed of $\mathrm{Si}, \mathrm{Al}, \mathrm{Fe}$, 
and $\mathrm{K}$, which are typical constituents of aluminosilicates such as biotite, $\mathrm{K}(\mathrm{Mg}, \mathrm{Fe})_{3}\left[\mathrm{AlSi}_{3} \mathrm{O}_{10}\right](\mathrm{OH}, \mathrm{F})_{2}$ and vermiculite, $(\mathrm{Mg}, \mathrm{Fe}, \mathrm{Al})_{3}\left[(\mathrm{Al}, \mathrm{Si})_{4} \mathrm{O}_{10}\right](\mathrm{OH})_{2} 4 \mathrm{H}_{2} \mathrm{O}$. The data was utilized to calculate weathering index of the sample. The chemical index of alteration (CIA):

$$
(\mathrm{CIA})=100 \times\left[\mathrm{Al}_{2} \mathrm{O}_{3} /\left(\mathrm{Al}_{2} \mathrm{O}_{3}+\mathrm{CaO}+\mathrm{Na}_{2} \mathrm{O}+\mathrm{K}_{2} \mathrm{O}\right)\right] \quad(\text { Equation } 2)
$$

was used to characterize the estuary samples (Nesbitt and Young, 1982; Price and Velbel, 2003). $\mathrm{Na}_{2} \mathrm{O}$ was not included in the calculation, because $\mathrm{Na}_{2} \mathrm{O}$ was not analyzed by XRF. The modified CIA indices of the estuary samples ranged from 82 to 84 . The CIA index indicates the extent of the weathering of rock in the river basin. The values were only slightly different among the estuary samples. Because the difference of the CIA index among the samples collected from the same river basin is typically less than $10 \%$ (Borges et al., 2007; Vubaet al., 2013), the source of the estuary sediments was the same.

Vertical sectional SEM images of the polished estuary specimens C (Fig. SI4a) and D (Fig. SI4b) showed that the platy particles are preferably oriented parallel to the layered texture in larger deposit. An enlarged image revealed that a biotite grain was partially weathered on the edge (Fig. SI4c). In both samples $\mathrm{C}$ and $\mathrm{D}$, the particle size was $<\sim 100 \mu \mathrm{m}$ and submicron-sized particles with various contrast formed aggregates as large as $\sim 20 \mu \mathrm{m}$ (indicated by arrows in Fig. SI4d). Elemental maps of a portion of sample D (Fig. SI4e) revealed that aluminosilicates such as mica, clays and feldspar were dominant, and Fe-oxides and Mn-oxides were present as minor components. Soluble radioactive isotopes would adsorb to these oxides in the sequential extraction procedure. Marine-delivered elements, such as $\mathrm{Cl}$ and $\mathrm{S}$ (as sulfate), were not detected, indicating that these estuary samples were transported only by river water that was not mixed with seawater.

3.2. Distribution of the radioactive Cs in the estuary sediments 
The digital photograph and autoradiograph of the cross-section of the estuary sample C molded in resin are shown in Figures SI5a and b, respectively. Because the Kuma River estuary was hit by the tsunami that occurred on March 11, 2011, it is assumed that all estuary sediments formed before the earthquake were removed. A random distribution of radioactive Cs particle was observed in the autoradiograph. All cross section samples also showed the heterogeneous distribution of radioactivity with higher density near the bottom, indicating that the radioactivity is heterogeneous and has declined with time. Gamma spectrometry of the bulk samples revealed the peaks of ${ }^{134} \mathrm{Cs}$,

${ }^{137} \mathrm{Cs}$, and ${ }^{40} \mathrm{~K}$ (data not shown), and the radioactivity of ${ }^{40} \mathrm{~K}$ was about 30 times less than that of ${ }^{137} \mathrm{Cs}$, confirming that the dark spots in Fig. SI5b represent the location of radioactive ${ }^{134} \mathrm{Cs}$ and ${ }^{137}$ Cs.

In order to obtain undisturbed distribution of the particles associated with radioactive Cs, all of the estuary samples were mechanically split and the unpolished flat surface were analyzed by autoradiography. A larger number of particles were associated with radioactive Cs found in the lower portion of the sediment column, as compared with the upper portion (Fig. SI5c). On the other hand, sample D showed homogeneous distribution of the particle associated with radioactive Cs. In order to quantitatively evaluate the vertical distribution of the particles associated with radioactive Cs, the platy estuary samples A-C were horizontally divided into two plates: $\sim 1 \mathrm{~cm}$ from bottom and the rest from the upper portion. Sample D was analyzed without separation. As summarized in Table SI4, the ${ }^{137} \mathrm{Cs}$ radioactivity concentration of lower layer was $\sim 38 \mathrm{~Bq} \mathrm{~g}^{-1}$, while that of upper layer was $\sim 28$ $\mathrm{Bq}^{-1}$. The ratio of radioactivity concentration of upper to lower layers was $\sim 0.7$.

\subsection{Sequential extraction of radioactive Cs in estuary sediments}

The ${ }^{137} \mathrm{Cs}$ concentration of four estuary samples varied from 28.1 to $37.5 \mathrm{~Bq} \mathrm{~g}^{-1}$ and that of a beach sand sample collected from the bottom of an estuary sediment was $3.70 \mathrm{~Bq} \mathrm{~g}^{-1}$. Physical 
property and radioactive cesium concentration of the samples are summarized in Table SI2. Since the gamma spectrometry for ${ }^{134} \mathrm{Cs}$ exhibits values with less accuracy due to presence of the sum peaks of ${ }^{134} \mathrm{Cs},{ }^{137} \mathrm{Cs}$ radioactivity was used for quantification and the following discussion on the chemical form of the radioactive Cs in the estuary samples. Figure 3 shows the results of sequential extraction on four estuary sediments as compared with those of one river sediment and six surface soils. The ${ }^{137} \mathrm{Cs}$ radioactivity of water soluble fraction (F1) was below the detection limit for all samples, while that of F6-residual fraction of estuary and riverbed sediments was as high as $\sim 90 \%$ of the total ${ }^{137} \mathrm{Cs}$ radioactivity. The F6 fraction corresponds to an insoluble form of radioactive Cs left after the series of extractions. Radioactive Cs in this faction is present as a form rigidly bound to clays and/or the frayed edge sites of weathered mica. In the estuary samples, the ${ }^{137} \mathrm{Cs}$ activities of the other fractions (F1 F5) were less than $5 \%$ of the total ${ }^{137} \mathrm{Cs}$. On the other hand, the F6 fraction of surface soils was less than $85 \%$, and Fukaya sample exhibited the lowest value of $62 \%$ of the total ${ }^{137} \mathrm{Cs}$ radioactivity. An autoradiographic image of estuary sample $\mathrm{C}$, which was dried residue after sequential extraction, confirmed that the highly radioactive particles remained as the insoluble form even after the entire extraction process (Fig. SI6).

\subsection{Desorption experiment in simulated seawater}

Estuary sediment leached 10 times used in the desorption experiment were not affected by seawater prior to the experiment, since $\mathrm{NaCl}$ distribution, which is derived from sea salt, was minimal in the sample (Fig. SI4e). In the desorption experiment, the total cumulative ${ }^{137} \mathrm{Cs}$ radioactivity $\left(\mathrm{Bq}^{-1}\right)$ leached to the solution was calculated after each desorption treatment as summarized in Table SI5. Initial ${ }^{137} \mathrm{Cs}$ radioactivity in $0.8 \mathrm{~g}$ of the estuary sample was $23.9 \mathrm{~Bq}$ and $3.4 \pm 0.6 \%$ of total ${ }^{137} \mathrm{Cs}$ was desorbed from the soil sample in average (12 replicates) after the fourth cycle of desorption treatments, which corresponds to six hours of the total incubation time. 
After the third leaching treatment, the total amount of the desorbed ${ }^{137} \mathrm{Cs}$ remained constant and the radioactive Cs did not further desorb into the artificial seawater, even after 1 month.

\section{Discussion}

\subsection{Physico-chemical properties of the estuary sediment}

Estuary samples collected in the present study provided a unique opportunity to evaluate chemical forms of radioactive Cs transported during flood events. It was assumed that the slightly elevated area of the beach $(\sim 1 \mathrm{~m})$ accumulated flood sediment because river water covered this area during the flood events. It was difficult to specify date and number of the flood event along the Kuma river ; however, there are evidence of multiple flood events from our results in addition to the other study near the Kuma River (Nagao et al., 2013; Yamashiki et al., 2014): (i) the dried platy sediments can be easily cleaved along the horizontal bedding planes in the middle of the layers even though the mineral assemblage with a slight gap (indicated by black arrows in Figures SI4a and b) and the particle size distribution revealed that there is no change of the size distributions of sediment particles between the upper and lower layers as revealed by SEM analysis (Figures SI4a and b), suggesting that the particle settling rapidly occurred a few times without a sorting process; and, (ii) the distribution of particles associated with radioactive Cs is very different between the cleaved plates without size fractionation. A large number of particles associated with radioactive Cs are concentrated in the lower portion of the samples A through C (Fig. SI5c), whereas much fewer particles bound to radioactive Cs were present in the upper layer. Sample D exhibited a low concentration of radioactive Cs particles similar to that in the upper layer of sample A-C (Table SI4). Considering the slightly higher location for collection of sample D when compared to that samples A-C, it is likely that the sediment particles in the sample D correspond to the upper portion of the other samples. Thus, it is anticipated that the estuary sediments formed from suspended soils 
containing a large number of particles associated with radioactive Cs after March 11, 2011, followed by another flooding event in which fewer particles bound to radioactive Cs were transported. Indeed, the modified CIA index of sample D is different from that of the samples A-C, indicating that the chemical composition is slightly different between the former and latter flooding events. We infer that the radioactive Cs flux after multiple flood events dramatically decreased with time since 2011, which is consistent with the previous study reporting the radioactivity concentration of the suspended soils decreased with time (Sakaguchi et al., 2015).

The median value of particle size and the size distribution of particles in the four estuary samples ranged from 28 to $32 \mu \mathrm{m}$ and 5-100 $\mu \mathrm{m}$, respectively (Fig. SI3), which is in good agreement with the size determined from the SEM images. In the laser diffraction particle size analyzer, particle diameter is determined based on the Mie scattering theory in laser diffraction (Mie 1908). Thus, in principle, the particle or aggregate that exhibits the same laser diffraction characteristics of an ideal sphere is considered to have the same diameter of the ideal spherical particle, meaning that the irregular particle shape (Figures SI4a and b) might result in a wider distribution of the measured particle size of the estuary samples. The size range in the estuary sample is comparable to or slightly greater than that previously reported ( 3 to $63 \mu \mathrm{m}$ ) for the suspended soil in the Abukuma River and the Kuchibuto River in Fukushima, which are tributaries of the Abukuma River (Sakaguchi et al., 2015). The flooded river water should have transported larger-sized particles than the normal suspended soils, which might result in the slightly larger size range.

4.2. Behavior of ${ }^{137} \mathrm{Cs}$ in the estuary sediment

Ninety percent of ${ }^{137} \mathrm{Cs}$ in estuary sediment was bound to the residual fraction that is mainly composed of sheet silicates and clays with 10 or $14 \AA$ d-spacings. Even after the series of sequential extraction treatments, the distribution of ${ }^{137} \mathrm{Cs}$ appeared unchanged and heterogeneous (Fig. SI6), 
indicating that the ${ }^{137} \mathrm{Cs}$ is transported as clay particles. Cesium-137 can be strongly bound to sheet silicates, especially at the frayed edge site (FES) (Sawhney, 1970; Cremers et al., 1988; Qin et al., 2012; Hirose et al., 2015; Yamada et al., 2015), because the FES rigidly incorporates dehydrated Cs ions into the cation sites that are of comparable ionic size in the negatively charged inter-layers (Kogure et al., 2012; Fuller et al., 2015).

The proportion of ${ }^{137} \mathrm{Cs}$ bound to sheet silicates (F6) in the estuary samples (Kuma) and riverbed sample (Odaka) was greater than that in the soil samples (Fig. 3), which implies that the total ${ }^{137} \mathrm{Cs}$ in the residual component (F6) increased in the estuary sediments assuming that the soil samples represent those from the contaminated area in Fukushima prefecture. The increase in F6 fraction in the estuary and the river-bed sediments could be a result of several processes. One is the enrichment of small particles (silt size) in the estuary and the river-bed sediments compared with the soil samples during transportation through the river system. Indeed, Tanaka et al. (2015) proposed the size redistribution of particles associated with the radioactive Cs during the physical transport process through the Abukuma River in Fukushima. Because the amount of clay minerals is enhanced in the silt size fraction, it is likely that the re-distribution of particle size occurred in the Kuma River system, resulting in the higher F6 values of estuary sediments compared with that of surface soils. In fact, the estuary sediment did not reveal any large particles $(>100 \mu \mathrm{m})$ (Fig. S3).

The other possible factor is desorption and re-adsorption of radioactive Cs to the clay minerals that is the component of F6 fraction. A small component of the water soluble fraction (F1) remained in the soil samples, whereas this fraction in the estuary sediments was less than the detection limit. This indicates that the small amount of radioactive Cs loosely bound as F1 fraction in the soil was released to the surrounding water, and/or re-sorbed onto clay minerals in the residual fraction (F6). The proportion of ion exchangable fraction (F2) decreased in the estuary sediments as shown in Fig. 3. It is commonly known that Cs bound to clay minerals hardly desorbs in cationic solutions with 
typical concentrations of natural waters (Yoshikawa et al., 2014; Sakaguchi et al., 2015; Mishra et al., 2015). Thus, it can be inferred that the dissociation of ${ }^{137}$ Cs from F2-F5 should not occur during the transport through the river; however, the estuary sediments might have experienced various processes including interaction with the river water, physical abrasion of the mineral surfaces, and multiple wet/dry cycles before and/or after transportation, which can change the ionic strength in the pore water.

4.3. Implication for ${ }^{137} \mathrm{Cs}$ desorption from the suspended soil particles in the ocean

Considering that the estuary sample is representative of the bulk of material transported to the ocean during flooding events, the results of desorption experiments provide insight into the fate of suspended particles associated with ${ }^{137} \mathrm{Cs}$ in the ocean. First, the artificial seawater in the present experiment was refreshed every 2 hours to simulate an infinitely large volume of seawater. These results suggest that $3.4 \%$ of ${ }^{137} \mathrm{Cs}$ was desorbed in the artificial seawater within 8 hours, but re-adsorption onto sheet silicates is negligible when ${ }^{137} \mathrm{Cs}$ desorbed in seawater is diluted by stable Cs in seawater. Takata et al. (2015) also examined the desorption process of radioactive Cs in filtered seawater and estimated that up to $0.75 \sim 6.6 \%$ of radioactive Cs desorbed within seven days, which is consistent with the desorbed proportion estimated in the present study. Thus, the proportion of desorption-ready fraction of ${ }^{137} \mathrm{Cs}$ in seawater determined in the present study can be used to estimate the amount of soluble and particulate forms of radioactive Cs in the ocean. Based on a report by Yamashiki et al. (2014) estimating 5.74 TBq of ${ }^{137} \mathrm{Cs}$ discharged into the Pacific Ocean from Abukuma River during August 2011 to May 2012, the total amount of soluble ${ }^{137} \mathrm{Cs}$ can be calculated to be $0.21 \mathrm{TBq}$ during the period, while $5.53 \mathrm{TBq}$ of ${ }^{137} \mathrm{Cs}$ remained bound to clay particles. 
The desorbed ${ }^{137} \mathrm{Cs}(3.4 \%)$ in the seawater is in good agreement with the proportion of the ion exchangeable fraction (F2), $3.4 \pm 0.6 \%(\mathrm{n}=12)$. Because of the high $\mathrm{Na}$ ion concentration in seawater (see Table SI3), Na ion must play a similar role to that of ammonium ion, exchanging with Cs ion. In general, the ion-exchangeable fraction corresponds to the form weakly bound to planer sites or edge sites of sheet silicates (Dzene et al, 2015), and the $\mathrm{Na}^{+}$can barely exchange with Cs ion in the interlayer (Liu et al., 2003). Although a few theoretical studies based on first principle calculations have proposed that single $\mathrm{Na}^{+}$can replace a single $\mathrm{Cs}$ ion at the edge of the interlayer (Okumura et al., 2013), this requires that $\mathrm{Na}^{+}$overcome a significant energy barrier to the diffusion and replacement of tightly bound $\mathrm{Cs}$ ion in the interlayer of sheet silicate. Thus, such desorption processes occur at an extremely slow rate or never happen at all in very dilute Cs concentrations. Indeed, the desorbed Cs ion in solution remained constant over the period of the present experiment, indicating that the large portion of ${ }^{137} \mathrm{Cs}>96 \%$ is tightly bound to the clays and will remain attached to these particles in the ocean. Therefore, the behavior of radioactive Cs in the oceanic water is mainly governed by physical processes such as Stoke's law and marine parameters including the current velocity in the near coastal region (Honda et al., 2013). Since transport of particles associated with radioactive $\mathrm{Cs}$ in the ocean is one of the dominant migration processes, the size of the suspended particles is a key factor in determining the retention time and the lateral and vertical distribution of radioactive $\mathrm{Cs}$ in the ocean.

\section{Conclusion}

Four estuary sediment samples from Kuma River that were the result of the accumulation of suspended soils after multiple storm events following the tsunami, were investigated utilizing a variety of bulk and micro-analytical techniques. Kuma River Estuary sediments were mainly composed of quartz and aluminosilicates such as mica, clays, and feldspar in the size range of 5-100 
$\mu \mathrm{m}$. Radioactive Cs was distributed heterogeneously as particulates. Radioactivity concentration of the upper layer in the sequence of flood deposits was $\sim 30 \%$ less than the lower layer, suggesting lesser amounts of particles associated with radioactive Cs were transported in river water during storm events with the passage of time. As compared with paddy soils, the estuary samples had a larger proportion ( $\sim 90 \%$ ) of the ${ }^{137} \mathrm{Cs}$ tightly bound to weathered mica and clays. This observation is attributed to two possible processes: first is the selective transportation of fine clay particles associated with radioactive Cs and then deposition on the river and/or estuary, second is the desorption of the other chemical form such as ion exchangeable fractions and possible re-adsorption to clays prior to the deposition. Based on desorption experiments, we suggest that for soils suspended and transported in river water, approximately $3.4 \%$ of ${ }^{137} \mathrm{Cs}$, corresponding to the ion-exchangeable fraction, is available within 8 hours. Most of the ${ }^{137} \mathrm{Cs}$ remains bound to clays after transported to the ocean; thus, the migration and distribution of radioactive Cs depend mainly on the size, shape and density of the particles, and the interaction of these particles with coastal currents.

\section{Acknowledgements}

This study in part was financially supported by Ministry of Education, Culture, Sports, Science and Technology, Japan (SY and SU). SU is also supported by JST Initiatives for Atomic Energy Basic and Generic Strategic Research, and ESPEC Foundation for Global Environment Research and Technology (Charitable Trust) (ESPEC Prize for the Encouragement of Environmental Studies). The authors are grateful to Dr. Watanabe for her assistance on SEM and XRD analyses at the Center of Advanced Instrumental Analysis, Kyushu University. The authors are also indebted to Professor Onda of the University of Tsukuba for his assistance on the particle size analysis. 
Reference

Afonin VP, Finkelshtein AL, Borkhodoev VYa, Gunicheva TN. X-ray analysis of rocks by the fundamental parameter method. X-Ray Spectrom 1992; 21: 69-75.

Aoyama M, Tsumune D, Uematsu M, Kondo F, Hamajima Y. Temporal variation of ${ }^{134} \mathrm{Cs}$ and ${ }^{137} \mathrm{Cs}$ activities in surface water at stations along the coastline near the Fukushima Dai-ichi Nuclear Power Plant accident site, Japan. Geochem J 2012;46:321-5.

Borges J, Huh Y. Petrography and chemistry of the bed sediments of the Red River in China and Vietnam: Provenance and chemical weathering. Sediment Geolog 2007; 194(3-4): 155-68.

Borkhodoev VY. Accuracy of the fundamental parameter method for x-ray fluorescence analysis of rocks. X-Ray Spectrom 2002; 31:209-18.

Chino M, Nakayama H, Nagai H, Terada H, Katata G, Yamazawa H. Preliminary Estimation of Release Amounts of ${ }^{131} \mathrm{I}$ and ${ }^{137} \mathrm{Cs}$ Accidentally discharged from the Fukushima Daiichi Nuclear Power Plant into the atmosphere. J Nucl Sci Technol 2011;48(7):1129-34.

Cremers A, Elsen A, De Preter P, Maes A. Quantitative analysis of radiocaesium retention in soils. Nature 1988;335:247-9.

Dzene L, Tertre E, Hubert F, Ferrage E. Nature of the sites involved in the process of cesium desorption from vermiculite. J Collid Interface Sci 2015;455:254-60. 
Evrard O, Chartin C, Onda Y, Lepage H, Cerdan O, Lefevre I et al. Renewed soil erosion and remobilization od radioactive sediment in Fukushima coastal rivers after the 2013 typhoons. Sci Report 2014;4(4574):1-5.

Fujiwara T, Saito T, Muroya Y, Sawahata H, Yamashita Y, Nagasaki S, et al. Isotopic ratio and vertical distribution of radionuclides in soil affected by the accident of Fukushima Dai-ichi nuclear power plants. J Environ Radioactivity 2012;113:37-44.

Fuller JA, Shaw S, Ward BM, Haigh JS, Mosselmans WJF, Peacock LC, et al. Caesium incorporation and retention in illite interlayers. Appl Clay Sci 2015;108:128-34.

Hirose M, Kikawada Y, Tsukamoto A, Oi T, Honda T, Hirose K et al. Chemical forms of radioactive Cs in soils originated from Fukushima Dai-ichi nuclear power plant accident studied by extraction experiments, J. Radioanal Nucl Chem 2015; 303: 1357-9.

Honda, MC, Kawakami H, Watanabe S, Saino T, Concentration and vertical flux of Fukushima-derived radiocesium in sinking particles form two sites in the Northwestern Pacific Ocean. Biogeosciences 2013; 10: 3525-34.

Hou LX, Fogh LC, Kucera J, Andersson GK, Dahlgaard H, Nielsen PS. Iodine-129 and Caesium-137 in Chernobyl contaminated soil and their chemical fractionation. Sci Total Environ 2003;308:97-109. 
Kaneko M, Iwata H, Shiotsu H, Masaki S, Kawamoto Y, Yamasaki S, et al. Radioactive Cs in the severely contaminated soils near the Fukushima Daiichi nuclear power plant. Front Energy Res 2015;3:37,1-10.

Kato H, Onda Y, Teramage M. Depth distribution of ${ }^{137} \mathrm{Cs},{ }^{134} \mathrm{Cs}$, and ${ }^{131} \mathrm{I}$ in soil profile after Fukushima Dai-ichi Nuclear Power Plant accident. J Environ Radioactivity 2012;111:59-64.

Kogure T, Morimoto K, Tamura K, Sato H, Yamagishi A. XRD and HRTEM evidence for fixation of cesium ions in vermiculite clay. Chem Lett 2012;41(4):380-2.

Kozai N, Ohnuki T, Arisaka M, Watanabe M, Sakamoto F, Yamasaki S, et al. Chemical states of fallout radioactive Cs in the soils deposited at Fukushima Daiichi Nuclear Power Plant accident. J Nucl Sci Technol 2012;49(5):473-8.

Liu C, Zachara JM, Smith SC, McKinley JP, Ainsworth CC. Desorption kinetics of radiocesium from subsurface sediments at Hanford Site, USA. Geochim Cosmochim Acta 2003;67(16):2893-912.

MEXT: Japanese Ministry of Education, Culture, Sports, Science and Technology; http://www.mext.go.jp/english, accessed on Nov 07, 2014.

Mie G.Contributions to the optics of diffuse media, especially colloidal metal solutions. Ann Phys 1908; 25: 377-445.

Minoura K, Yamada T, Hirano S, Sugihara S. Movement of radiocaesium fallout released by the 
2011 Fukushima nuclear accident. Nat Hazards 2014;73:1843-62

Mishra S, Arae H, Sorimachi A, Hosoda M, Tkonami S, Ishikawa T, et al. Distribution and retention of Cs radioisotopes in soil affected by Fukushima nuclear plant accident. J Solids Sediments $2015 ; 15: 374-80$.

Nagao S, Kanamori M, Ochiai S, Tomihara S, Fukushi K, Yamamoto M. Export of ${ }^{134} \mathrm{Cs}$ and ${ }^{137} \mathrm{Cs}$ in the Fukushima river systems at heavy rains by Typhoon Roke in September 2011. Biogeosciences 2013;10:6215-23.

Nesbitt HW; Young GM. Early Proterozoic climates and plate motions inferred from major element chemistry of lutites. Nature 1982;299:715-717.

NRA: Nuclear Regulation Authority, http://radioactivity.nsr.go.jp/en/list/257/list-1.html, accessed on Mar 21, 2012.

Okumura M, Nakamura H, Machida M. Mechanism of strong affinity of clay minerals to radioactive cesium: first-principles calculation study for adsorption of cesium at frayed edge sites in muscovite. J Phys Soc Jpn 2013; 82(033802):1-5.

Price J, Velbel MA. Chemical weathering indices applied to weathering profiles developed on heterogeneous felsic metamorphic parent rocks. Chem Geol 2003;202:397-416. 
Qin H, Yokoyama Y, Fan Q, Iwatani H, Tanaka K, Sakaguchi A, et al. Investigation of cesium adsorption on soil and sediment samples from Fukushima Prefecture by sequential extraction and EXAFS technique. Geochem J 2012; 46: 297-302.

Saito T, Makino H, Tanaka S. Geochemical and grain-size distribution of radioactive and stable cesium in Fukushima soils: Implications for their long-term behavior, J. Environ. Radioactivity 2015; 138: 11-8.

Sakaguchi A, Tanaka K, Iwatani H, Chiga H, Fan Q, Onda Y et al. Size distribution studies of ${ }^{137} \mathrm{Cs}$ in river water in the Abukuma Riverine system following the Fukushima Dai-ichi Nuclear Power Plant accident. J Environ Radioactivity 2015;139:379-89.

Sawhney BL. Potassium and cesium ion selectivity in relation to clay mineral structure. Clays Clay Miner 1970;18(1):47-52.

Takahashi J, Tamura K, Suda T, Matsumura R, Onda Y. Vertical distribution and temporal changes of ${ }^{137} \mathrm{Cs}$ in soil profiles under various land uses after the Fukushima Dai-ichi Nuclear Power Plant accident. J Environ Radioactivity 2015;139:351-61.

Takata H, Hasegawa K, Oikawa S, Kudo N, Ikenoue T, Isono SR et al. Remobilization of radiocesium on riverine particles in seawater: The contribution of desorption to the export flux to the marine environment. Marine Chem. 2015;176:51-63.

Tanaka K, Iwatani H, Sakaguchi A, Fan QH, Takahashi Y. Size-dependent distribution of 
radiocesium in riverbed sediments and its relevance to the migration of radiocesium in river systems after the Fukushima Daiichi Nuclear Power Plant accident. J Environ Radioactivity 2015;139:390-7.

Tazoe H, Hosoda M, Sorimachi A, Nakata A, Yoshida AM, Tokonami S, et al. Radioactive pollution from Fukushima Daiichi nuclear power plant in the terrestrial environment. Radi Protec Dosim 2012;152(1-3):198-203.

TEPCO report; www.nsr.go.jp/data/000051207.pdf, (in Japanese), 2012.

Teramage TM, Onda Y, Patin J, Kato H, Gomi T, Nam S. Vertical distribution of radiocesium in coniferous forest soil after the Fukushima nuclear power plant accident. J Environ Radioactivity 2014;137:37-45.

Teranaka K, Yasuda T, Nagabayashi H, Hamada Y, Matsumura N. Fukushimaken kasen no kakou genchi tyousa (in Japanese). Proc Coastal Eng, JSCE 1990;37:349-53.

Tessier A, Campbell PGC, Bisson M. Sequential extraction procedure for the speciation of particulate trace metals. Anal Chem 1979;51(7):844-51.

Ueda S, Hasehawa H, Kakiuchi H, Akata N, Ohtsuka Y, Hisamatsu S. Fluvial discharges of radiocaesium from watersheds contaminated by the Fukushima Dai-ichi Nuclear Power Plant accident, Japan. J Environ Radioactivity 2013;118:96-104. 
Vuba S, Farnaaz S, Sagar N, Ahmad SM. Geochemical and mineralogical characteristics of recent clastic sediments from lower Godavari river: Implications of source rock weathering, J. Geolog. Soci. India. 2013; 82(3): 217-26.

Yamada S, Kitamura A, Kurikami H, Yamaguchi M, Malins A, Machida M. Sediment and ${ }^{137} \mathrm{Cs}$ transport and accumulation in the Ogaki Dam of eastern Fukushima, Environ Res Lett 2015; 10(014013): 1-10.

Yamaguchi M, Kitamura A, Oda Y, Onishi Y. Predicting the long-term ${ }^{137} \mathrm{Cs}$ distribution in Fukushima after the Fukushima Dai-ichi nuclear power plant accident: a parameter sensitivity analysis, J. Environ. Radioactivity 2014; 135: 135-46.

Yamashiki Y, Onda Y, Smith GH, Blake HW, Wakahara T, Igarashi Y, et al. Initial flux of sediment-associated radiocesium to the ocean from the largest river impacted by Fukushima Daiichi Nuclear Power Plant. Sci Reports 2014;4(3714):1-7.

Yoshikawa N, Obara H, Ogasa M, Miyazu S, Harada N, Nonaka M. ${ }^{137} \mathrm{Cs}$ in irrigation water and its effect on paddy fields in Japan after the Fukushima nuclear accident, Sci. Total. Environ 2014; 481: 252-9. 
Figure captions

Figure 1. A map showing the distribution of dose near the FDNPP. Sample locations at the Kuma River estuary and Odaka River are indicated by arrows 1 and 2. The map was prepared based on the airplane monitoring survey by MEXT in November 2014. Two river sediments (Kuma River and Odaka River) and six surface soil samples (Ogi Dam, Okaki Dam, Akougi, Iitoi, Fukaya and Maeda; arrows 3-8 in order) were collected. Detailed information on the samples were summarized in Table SI1.

Figure 2. (a) Powder X-ray diffraction patterns of four estuary samples and beach sand. (b) A diagram enlarged the region with lower 2 theta angle. The diffraction peaks derived from sheet silicates, i.e., 7.2, 10.1 and $14.3 \AA$ are emphasized by dashed lines. Qtz: quartz; Ab: albite; Or: orthoclase; An: anorthite; Ms: muscovite; Brt: barite; Mag: magnetite; Tr: tremolite.

Figure 3. A summary of the results of sequential chemical extractions giving the proportion of the different chemical forms of ${ }^{137} \mathrm{Cs}$ radioactivity in the estuary samples from the Kuma River as compared with that in riverbed sediment from the Odaka River and six surface soils. All the measurement errors of the gamma spectrometry were less than $0.1 \%$. 
Table 1. Chemical composition of the estuary sediment samples analyzed by XRF. Sodium and Mg were not included in the analysis because of the extremely low sensitivity of detector. The elemental compositions were calculated to be oxides and normalized to $100 \%$ in total. The CIA index represents the modified CIA index calculated by $100 \times\left[\mathrm{Al}_{2} \mathrm{O}_{3} /\left(\mathrm{Al}_{2} \mathrm{O}_{3}+\mathrm{CaO}+\mathrm{K}_{2} \mathrm{O}\right)\right]$ based on Nesbitt and Young (1982). $\mathrm{Na}_{2} \mathrm{O}$ was excluded in the calculation. STD in this table indicates one sigma standard deviation of three replication.

\begin{tabular}{ccccccccc}
\hline & \multicolumn{2}{c}{ Sample A } & \multicolumn{2}{c}{ Sample B } & \multicolumn{2}{c}{ Sample C } & \multicolumn{2}{c}{ Sample D } \\
& Contents / wt $\%$ & STD / $\%$ & Contents / wt $\%$ & STD / \% & Contents / wt $\%$ & STD / \% & Contents / wt \% & STD / \% \\
\hline $\mathrm{SiO}_{2}$ & 63.96 & 0.96 & 62.13 & 2.04 & 63.84 & 1.21 & 61.62 & 2.09 \\
$\mathrm{Al}_{2} \mathrm{O}_{3}$ & 21.41 & 3.59 & 23.15 & 2.33 & 21.49 & 3.94 & 23.35 & 2.13 \\
$\mathrm{Fe}_{2} \mathrm{O}_{3}$ & 7.46 & 2.39 & 7.67 & 1.99 & 7.58 & 2.19 & 8.09 & 2.15 \\
$\mathrm{CaO}$ & 2.40 & 0.52 & 2.38 & 0.48 & 2.51 & 0.55 & 2.35 & 0.49 \\
$\mathrm{~K}_{2} \mathrm{O}$ & 2.12 & 0.42 & 2.10 & 0.30 & 2.21 & 0.47 & 2.05 & 0.35 \\
$\mathrm{SO}_{3}$ & 1.47 & 0.95 & 1.38 & 0.76 & 1.19 & 0.58 & 1.36 & 0.87 \\
$\mathrm{TiO}_{2}$ & 0.72 & 0.16 & 0.75 & 0.14 & 0.77 & 0.20 & 0.76 & 0.13 \\
$\mathrm{MnO}$ & 0.21 & 0.07 & 0.21 & 0.05 & 0.21 & 0.06 & 0.23 & 0.06 \\
$\mathrm{BaO}$ & 0.17 & 0.15 & 0.16 & 0.14 & 0.06 & 0.11 & 0.13 & 0.11 \\
$\mathrm{ZrO}{ }_{2}$ & 0.01 & 0.02 & 0.00 & 0.00 & 0.00 & 0.00 & 0.00 & 0.00 \\
$\mathrm{SrO}$ & 0.02 & 0.01 & 0.02 & 0.01 & 0.02 & 0.01 & 0.02 & 0.01 \\
$\mathrm{ZnO}$ & 0.02 & 0.01 & 0.02 & 0.01 & 0.02 & 0.01 & 0.01 & 0.01 \\
$\mathrm{CuO}_{\mathrm{Rb}}$ & 0.02 & 0.01 & 0.02 & 0.00 & 0.02 & 0.01 & 0.01 & 0.01 \\
$\mathrm{Rb}_{2} \mathrm{O}$ & 0.01 & 0.00 & 0.01 & 0.00 & 0.01 & 0.00 & 0.01 & 0.01 \\
$\mathrm{As}_{2} \mathrm{O}_{3}$ & 0.00 & 0.00 & 0.00 & 0.00 & 0.00 & 0.00 & 0.00 & 0.00 \\
$\mathrm{Br}$ & 0.00 & 0.00 & 0.00 & 0.00 & 0.00 & 0.00 & 0.00 & 0.00 \\
$\mathrm{Y}_{2} \mathrm{O}_{3}$ & 0.00 & 0.00 & 0.00 & 0.00 & 0.00 & 0.00 & 0.00 & 0.00 \\
$\mathrm{~V}_{2} \mathrm{O}_{5}$ & 0.01 & 0.01 & 0.01 & 0.01 & 0.01 & 0.01 & 0.01 & 0.01 \\
$\mathrm{RuO}_{2}$ & 0.00 & 0.00 & 0.00 & 0.00 & 0.05 & 0.08 & 0.00 & 0.00
\end{tabular}




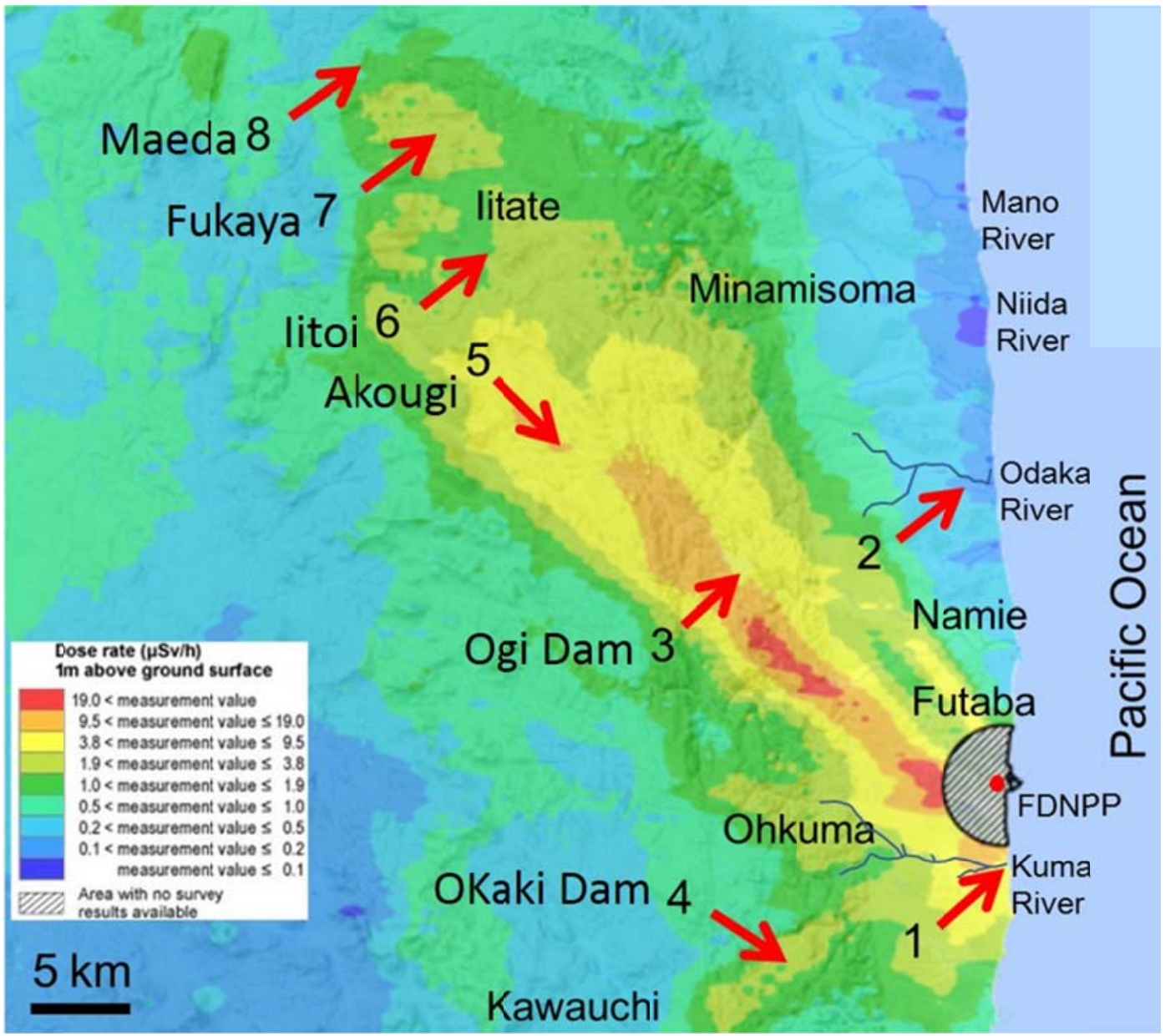

Figure1 

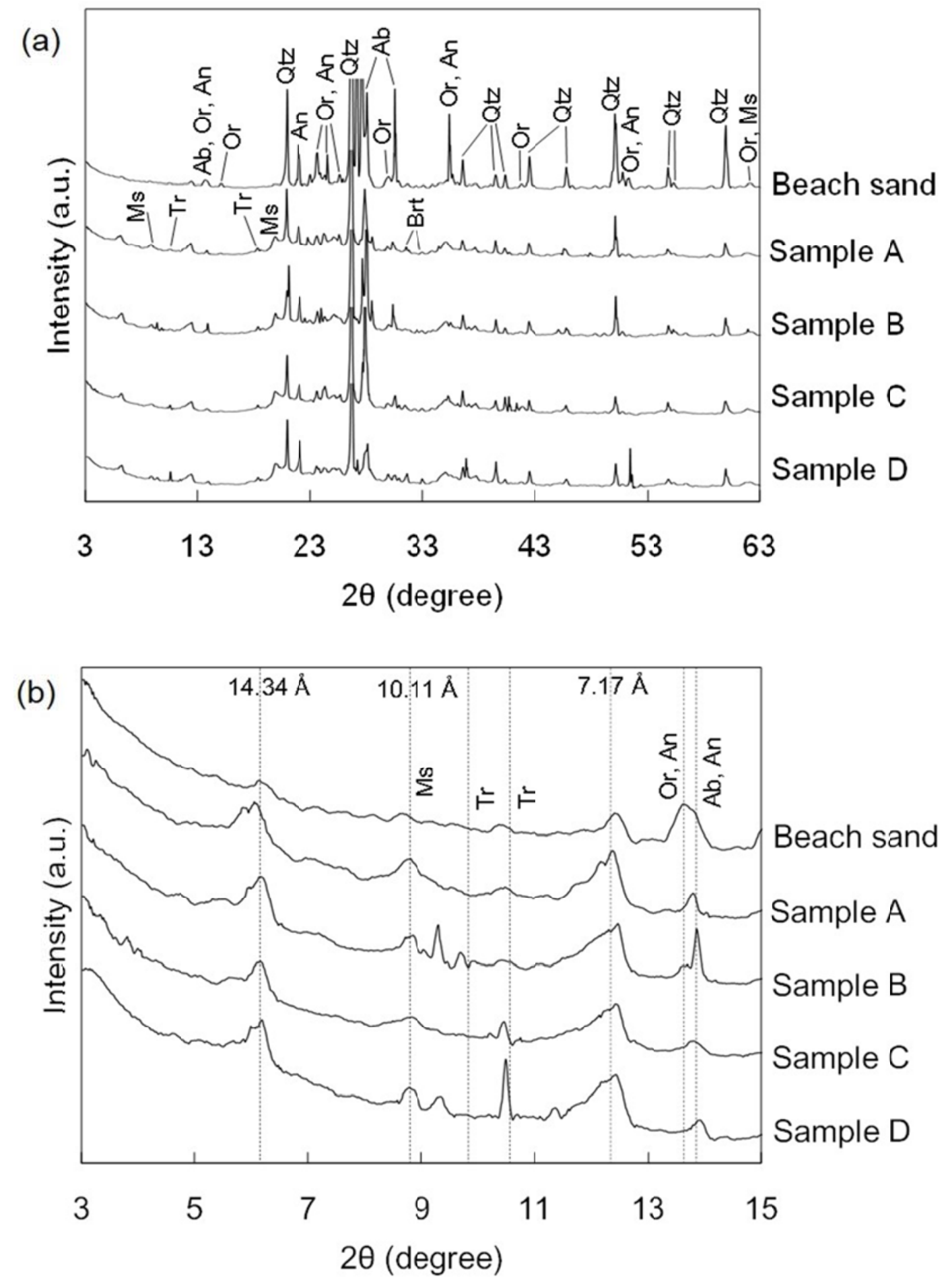

Figure 2 


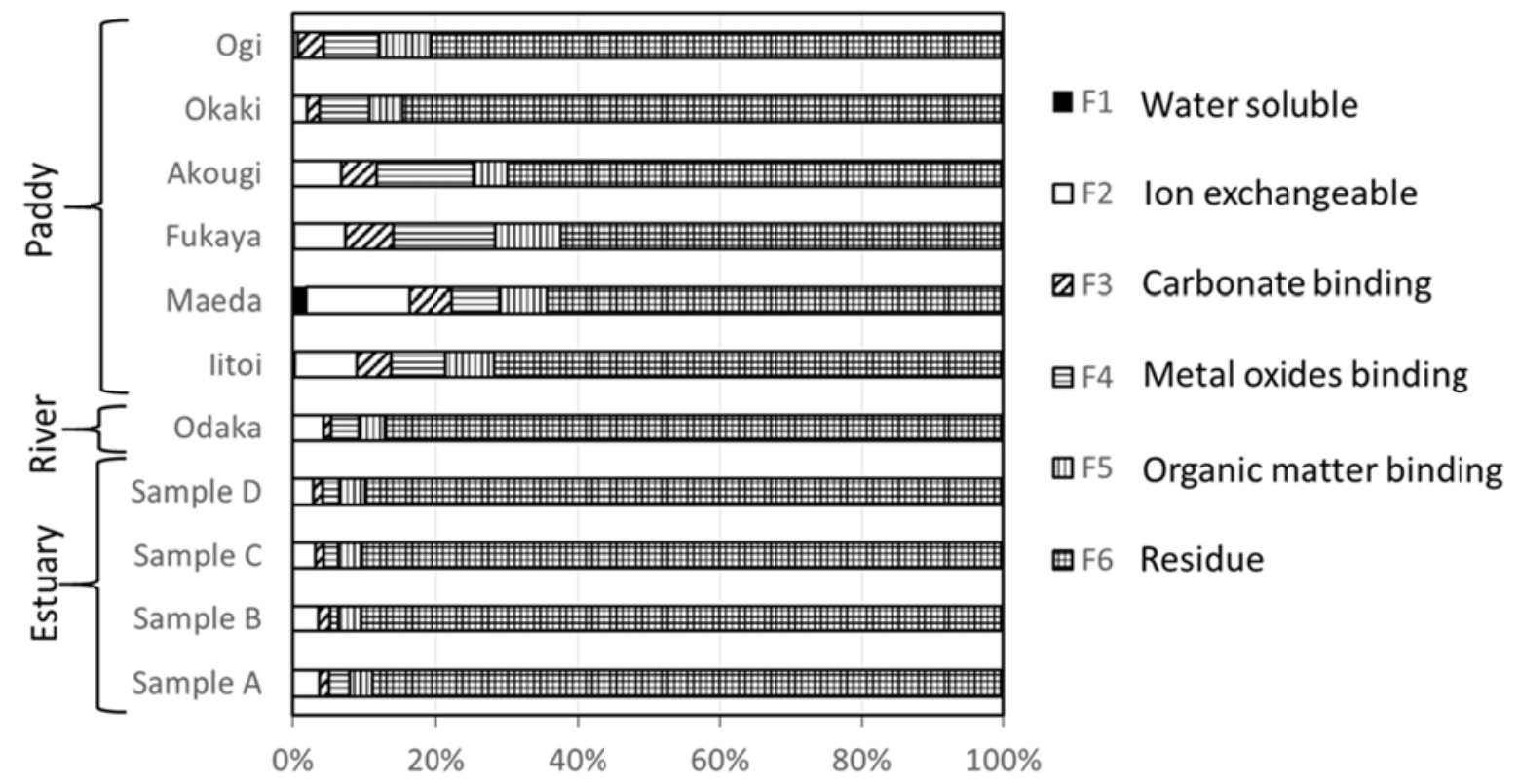

Figure 3 